A Spmic $_{\text {pectroscopy }}$

\title{
Review of In-situ Online LIBS Detection in the Atmospheric
} Environment

\author{
Qihang Zhang and Yuzhu Liu* \\ Jiangsu Key Laboratory for Optoelectronic Detection of Atmosphere and Ocean, Jiangsu Collaborative Innovation Center on Atmospheric Environment and \\ Equipment Technology (CICAEET), Nanjing University of Information Science \& Technology, Nanjing 210044, P. R. China
}

Received: June 21, 2021; Revised: August 24, 2021; Accepted: August 25, 2021; Available online: September 11, 2021.

DOI: $10.46770 / A S .2021 .609$

ABSTRACT: The aim of this review is to provide a brief introduction to recent research advances in in-situ online detection of atmospheric pollutants based on laser-induced breakdown spectroscopy (LIBS) under atmospheric environments. Atmospheric pollution has drawn much public attention, and there is increasing demand for rapid and accurate evaluation of atmospheric environments. LIBS has the advantages of in-situ online detection, simultaneous multi-element analysis, and noncontact measurement, making it a highly competitive analytical technique in the field of environmental monitoring. In terms of the different target samples, some typical research cases, including atmospheric particulate matter, atmospheric pollution sources, halogens in VOCs, atmospheric sulfur, and stable isotope abundance, are presented to illustrate the current development and problems of LIBS detection in this field.

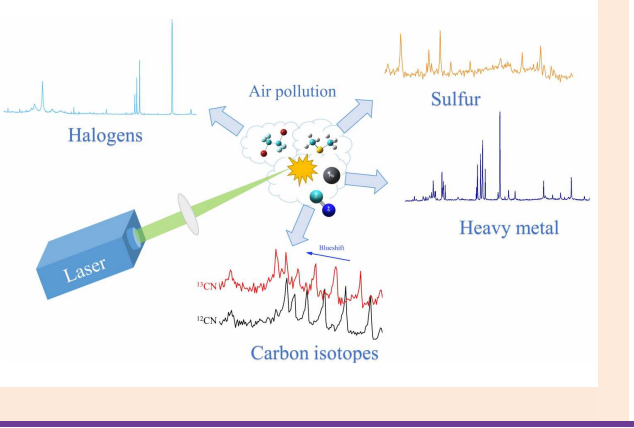

\section{INTRODUCTION}

In recent decades, there has been ever-increasing demand for the rapid detection of atmospheric pollutants, including volatile organic compounds (VOCs), heavy metals, $\mathrm{NO}_{x}$, and other hazardous substances, as the global atmospheric environment has worsened owing to natural changes and anthropogenic activities in many countries, and thus there has been ever-increasing demand for the rapid detection of these atmospheric pollutants. ${ }^{1}$ The presence of these atmospheric pollutants has caused serious atmospheric environmental problems such as haze, increased size of the ozone hole, and photochemical smog, and it has become a serious threat to the global ecological environment and human health, ${ }^{2,3}$ a problem that is gaining the attention of world governments. To solve these environmental problems or reduce their negative effects on the environment and human health, it is essential to first determine the composition of the atmosphere in a targeted area and then take specific measures after that. However, the types and concentrations of the components in the atmosphere vary from hour to hour with air flow. Hence, detection must be accomplished in a very short time to ensure the validity of further analysis and the timeliness of the measurement results, which is a great challenge for current detection methods.

Laser-induced breakdown spectroscopy (LIBS) is a wellknown atomic emission spectroscopy (AES) technique. In LIBS measurements, the target sample is ablated to a high-temperature plasma by a high-intensity pulse laser, and then the atomic, ionic, and molecular spectra containing the compositional information emitted from the plasma are qualitatively and quantitatively analyzed to determine all the components and their concentrations in the sample. ${ }^{4}$ LIBS has attracted significant attention since it was first reported at the $\mathrm{X}$ Colloquium Spectroscopicum Internationale by Brech and Cross in $1962 . .^{5}$ Shortly thereafter, Runge et al. established a calibration curve for quantitative analysis of target elements based on the intensity of the characteristic line and the plasma radiation mechanism, ${ }^{6}$ demonstrating that LIBS could be a useful tool for spectrochemical analysis. Over the past several decades, much scientific work covering a wide range of subjects has been carried out by research groups worldwide, ${ }^{7}$ and the basic theory of LIBS has gradually matured. Now, it has a wide variety of applications in many fields, such as in material sorting, ${ }^{8-12}$ coal analysis, ${ }^{13-16}$ food testing, ${ }^{17-19}$ medical testing, ${ }^{20-22}$ environmental monitoring, ${ }^{23-26}$ ocean exploration, ${ }^{27-30}$ and space exploration. ${ }^{31-33}$ 
Unlike current chemical analytical methods, LIBS is a novel optical analytical method with many distinguishing features, such as rapid and precise response, high sensitivity, small sample loss, and simultaneous multi-element analysis, and it is pollutionfree. ${ }^{34,35}$ These unique advantages make the LIBS technique an effective method for compositional analysis. Moreover, detection based on the LIBS technique requires no sample preparation, and it can be performed on gaseous, liquid, and solid samples under atmospheric pressure, ${ }^{36-38}$ which gives LIBS detection a great advantage over the current analytical techniques in terms of environmental detection. The elemental information of the sample can be determined according to the obtained emission spectra in a short time, providing real-time detection. Therefore, it is appropriate and promising to apply the LIBS technique to the insitu online detection of atmospheric environmental pollutants. However, compared with its application for the detection of liquid and solid samples, there are few publications on the detection of gaseous samples, especially in-situ detection under atmospheric pressure, because the low density of gas samples makes it difficult to observe the characteristic lines of the target element in the emission spectra. With the development of laser techniques and the theory of light-matter interaction, some novel LIBS techniques, such as femtosecond LIBS and dual-pulse LIBS, ${ }^{39-42}$ have been applied to improve the intensity and stability of the spectral signal. More and more studies are currently being carried out to improve the performance of the LIBS detection of gas, and the LIBS technique is playing an increasingly important role in the detection of atmospheric environmental pollution.

Research advances in LIBS applications in the field of environmental monitoring have been widely reported in many other reviews. ${ }^{43-46}$ This paper mainly introduces the development of atmospheric environment detection based on the LIBS technique in recent years. To adequately demonstrate the scientific research development of LIBS detection in an atmospheric environment, several typical cases are discussed to illustrate the current development and future trends in this field.

\section{EXPERIMENTAL}

A diagram of a typical LIBS system used for gas detection is shown in Fig. 1. The pulse laser is the core device of this system, and it plays a key role in the ablation of the target sample. As shown in Fig. 1, a nanosecond Nd:YAG laser system is used as the excitation laser, which is operated at a fundamental wavelength of $1064 \mathrm{~nm}$. Three dielectric lenses and a plano-convex lens are used to focus the laser pulse onto the target sample. An air pump is used to control the flow direction of the gas sample and ensure that the focus point is filled with the gas sample. The emission spectra emitted from the plasma are recorded using a spectrometer. Moreover, because bremsstrahlung caused by the collision of electrons in the plasma interferes with the atomic and molecular

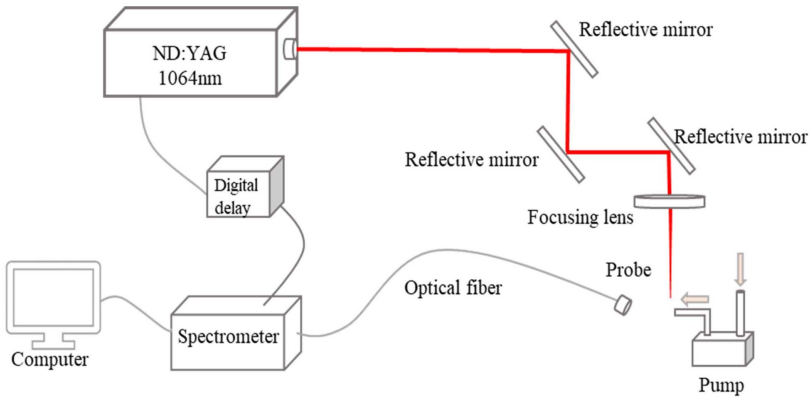

Fig. 1 Schematic diagram of the LIBS experimental apparatus for detection of gaseous sample.

emission, which contains the compositional information of the target sample, a digital delay is set between the spectrometer and laser system to control the integral delay time of each LIBS measurement and avoid the effect of background noise.

\section{CASE STUDIES}

Some studies have been conducted on the detection of atmospheric environments based on LIBS detection, most of which can be found in other reviews. ${ }^{47,48}$ In this review, some typical cases carried out in the last few years are carefully analyzed to illustrate the current development and problems in this field.

Atmospheric particulate matter analysis. Air quality is closely related to health. However, air quality has steadily declined because of the use of fossil fuels, and thus the air in many cities has reached a serious level of pollution. The main pollutant in most cities is floating particulates, which is the main reason for the formation of haze in the air. A variety of heavy metal elements exist in these atmospheric particulates, such as lead, mercury, chromium, arsenic, and cadmium. ${ }^{49}$ Once these heavy metal element particulates enter the human body through breathing, they do great harm to bodily health and can lead to diseases of the respiratory system, cardiovascular system, reproductive system, etc..$^{50}$ More seriously, these heavy metal pollutants are mostly nondegradable, and they could exist in the bodies of animals and plants for a long time, traveling up the food chain and causing more serious damage to the human body. Hence, the detection of heavy metal elements in atmospheric particulates based on the LIBS technique is worth studying.

It is difficult to directly perform LIBS measurements of particulate matter (PM) without any pretreatment because of the low density of PM samples in air. Many different preconcentration methods have been used to increase the hit efficiency of the laser pulse. The filter-based technique is a simple but useful tool to focus PM onto a membrane or substrate. Kwak et al. developed a LIBS experimental system with a particle collection substrate stage that could automatically move in a specific time interval. ${ }^{51}$ The detection results of the PM in every time interval were 
averaged to obtain time-resolved compositional information about the PM. Zhang et al. carried out research on the qualitative and quantitative detection of heavy metal elements in PM samples. ${ }^{52}$ The PM was collected using an air pump and focused onto a quartz fiber filter (QFF) membrane. The LIBS signal was greatly improved after this preconcentration. The recorded spectra showed clear spectral lines of $\mathrm{Na}, \mathrm{Al}, \mathrm{Si}, \mathrm{Cu}, \mathrm{Mg}$, and $\mathrm{Fe}$ in the emission spectra. In addition, the authors established a calibration curve of $\mathrm{Pb}$ using the internal standard method. However, the filter-based technique required a lot of time to extract the PM from the air, and thus the LIBS measurement could not be performed in real time or accomplished in a short time. Chances are that some pollutants that only existed for a short time were not observed in the spectra after the preconcentration process. In addition, the detection accuracy of the LIBS technique is greatly influenced by the matrix effect caused by the use of a substrate or filter membrane. To solve these problems, some new methods have been proposed to rapidly extract PM. Diwakar et al. designed an electrostatic aerosol collection system to collect particles for LIBS measurements. ${ }^{53}$ The aerosol particles were charged using a corona needle to which a $5-\mathrm{kV}$ positive potential was applied and then collected by the flat tip of a microneedle electrode. The particle capture efficiency was as high as $99 \%$ over a wide range of particle sizes, $30-600 \mathrm{~nm}$, using this aerosol collection system. The elements $\mathrm{Cd}, \mathrm{Cr}, \mathrm{Cu}, \mathrm{Mn}, \mathrm{Na}$, and $\mathrm{Ti}$ were simultaneously measured using LIBS, and a calibration curve was constructed by plotting the peak-to-base $(\mathrm{P} / \mathrm{B})$ ratio as a function of mass deposited on the collection needle tip. The limits of detection (LODs) of these elements were calculated to be 5.03, 0.035, 0.138, $0.155,0.018$ and $0.44 \mathrm{ng}$, respectively, at a flow rate of $1.5 \mathrm{~L} \mathrm{~min}^{-1}$ with sampling times of $5 \mathrm{~min}$. Similarly, Park et al. developed an aerosol-focusing LIBS system with sheath air focusing to determine the elemental composition of fine and ultrafine metal aerosol particles. ${ }^{54}$ Maeng et al. established a novel LIBS system with timed ablation and applied it to the determination of the elemental composition of individual airborne particles. ${ }^{55}$ Saari et al. studied the identification of fungal spores and bacteria particles in biological aerosols using an electrodynamic balance-assisted LIB electrodynamic balance (EDB) chamber. ${ }^{56}$ The above works demonstrate that preconcentration methods can improve the detection efficiency of the LIBS technique. However, even combined with these methods, the LIBS technique cannot realize the in-situ detection of PM.

Some researchers have attempted to improve conventional LIBS systems to enhance the detection capability of particles in specific environments. Xiong et al. studied the in-situ detection of $\mathrm{TiO}_{2}$ nanoparticle aerosols based on low-intensity phase-selective LIBS (PS-LIBS).${ }^{57}$ In novel, low-intensity LIBS measurements, the laser fluence as the excitation source is between the breakdown thresholds of the gas and particle phases. Hence, only the solid phase nanoparticles would break down, forming plasmas, without any surrounding gas-phase breakdown. PS-LIBS emissions were also enhanced with secondary resonant excitation by matching the excitation laser wavelength with an atomic transition line in the formed plasma. The enhancement factor of this method can be up to 220 times with advantageously selected lines. Heikkilä et al. studied single-particle elemental analysis of airborne aerosols by combining EDB trapping with the LIBS technique. ${ }^{58} \mathrm{~A}$ coronabased aerosol charger, double-ring EDB trap were imposed in the LIBS setup to increase the detection efficiency and reduce the LOD.

Atmospheric pollution sources. Clean air is a prerequisite not only for human life, but also for all life on the planet. However, a large number of emission sources of various environmental pollutants have seriously damaged the atmospheric environment and cause both local pollution and wide-area pollution. ${ }^{59-61}$ It is essential to understand the pollution source and the properties of the pollutants before taking measures. Studying the rapid online detection of these atmospheric pollutants is meaningful for determining emission sources and helpful for choosing the corresponding degradation methods according to the sources of pollution.

Coal is the major fuel used for producing electricity in many countries, and the emission of coal ash produced during the combustion of coal in the plant causes severe haze and acid rain. ${ }^{62}$ Zhu et al. therefore carried out a study on the quantitative analysis of $\mathrm{Fe}$ and the detection of multiple elements in coal ash via the LIBS technique. ${ }^{63}$ Taking $\mathrm{Al}$ as the reference element, a calibration curve of Fe concentration was established by plotting the relative intensity of $\mathrm{Fe}$ lines versus the Fe concentration in the coal ash based on the internal standard method. Then, the Fe concentration of unknown coal ash could be determined according to the calibration curve, and thus the sorting of coal ash could be rapidly realized. In addition, X-ray fluorescence spectrometry (XRF) was used to test the accuracy of the quantitative analysis based on LIBS measurements. Yin et al. studied the quantitative analysis of $\mathrm{Pb}$ in coal ash and the rapid detection of various metal elements, ${ }^{64}$ nonmetal oxides, and salts based on the LIBS technique, which is of great importance in coal utilization.

As a result of constant media attention and efforts made by government departments, many scientists have joined the study of wide-area pollution, and much research has been carried out. However, local pollution, which impacts people's daily lives, has seldom been stressed. The online detection of local air pollution is an important part of environmental protection and is beneficial to the health of people who work or live indoors.

Mosquito-repelling incense is often used to reduce biting in summer, where a large amount of smoke is emitted from the burning incense. It is noted that most brands of incense include Mn for the purpose of repelling mosquitoes. Although $\mathrm{Mn}$ is an essential trace element in the human body, excessive intake of Mn can cause neurological disorders in the brain and irreversible damage to the central nervous system. ${ }^{65,66} \mathrm{Qu}$ et al. studied the 
online real-time detection of smoke by using a mosquito-repelling incense as a representative example of local air pollution. ${ }^{67}$ Metal elements, including $\mathrm{Mg}, \mathrm{Fe}, \mathrm{Ca}$, and $\mathrm{Ti}$, as well as some toxic elements, such as $\mathrm{Sr}, \mathrm{Cr}$, and $\mathrm{Cd}$, were simultaneously observed in the spectra. Furthermore, there was also a characteristic spectral line of F I $(685.6 \mathrm{~nm})$ in the spectra, which proved the existence of meperfluthrin $\left(\mathrm{C}_{17} \mathrm{H}_{16} \mathrm{C}_{22} \mathrm{~F}_{4} \mathrm{O}_{3}\right)$ in the mosquito-repelling smoke. Moreover, the real-time detection of the ambient air via the LIBS technique and its effect on human breathing were also discussed to enlarge the scope of the developed LIBS system in the local environment.

Incense is widely used by people who practice Buddhism and Taoism in some developing countries or regions. Large quantities of inferior incense containing a variety of poisonous substances are extensively produced and sold by manufacturers because of its low cost. Hence, incense smoke causes local air pollution in indoor environments, especially in temples. Long-term exposure to these poisonous substances from burning incense can seriously damage the skin, respiratory system, and nervous system. ${ }^{68-69}$ Yin et al. studied the online and offline detection of incense smoke via LIBS. ${ }^{70}$ Mass spectrometry was also used to determine and analyze the elemental composition of incense smoke using a home-built single-particle aerosol mass spectrometer (SPAMS). Through measurements based on the combination of LIBS and SPAMS, the authors not only obtained elemental information but also identified the particle size and chemical composition of a single particle with extremely high temporal and spatial resolution.

There are many smokers worldwide, and it is generally known that cigarette smoking is harmful to one's health owing to the toxic ingredients in cigarettes. Moreover, cigarette smoking, which contains nicotine, tar, $\mathrm{Pb}$, As, and other noxious ingredients, also has pernicious effects on nonsmokers. ${ }^{71}$ Many studies have demonstrated that second-hand smoke can cause a wide range of diseases, such as lung cancer and heart attacks. ${ }^{72-74}$ Nonsmokers exposed to second-hand smoke have shown increased risk of heart disease by $25 \%-30 \%$ and lung cancer risk by $20 \%-30 \%$. ${ }^{75}$ Hence, it is important to accurately evaluate the local pollution caused by cigarette smoke in public areas. Zhang et al. carried out research on the in-situ detection of cigarette smoke in public areas. ${ }^{76}$ By using a strong pulse Nd:YAG laser ( $260 \mathrm{~mJ} /$ pulse) as the excitation source, LIBS was applied to the sidestream smoke of a burning cigarette. The characteristic lines of most metal elements, including $\mathrm{Mg}, \mathrm{Ca}, \mathrm{Sr}, \mathrm{Na}$, and $\mathrm{K}$, were observed in the obtained spectra, as shown in Fig. 2. Moreover, the matrix effect of the smoking detection was also discussed by comparing the LIBS spectra of cigarette smoke and cigarette ash.

Pollutants in the air, especially over a wide area, mostly originate from a variety of different sources. ${ }^{77-79}$ For example, the haze that occurs frequently in cities is a mixture of construction
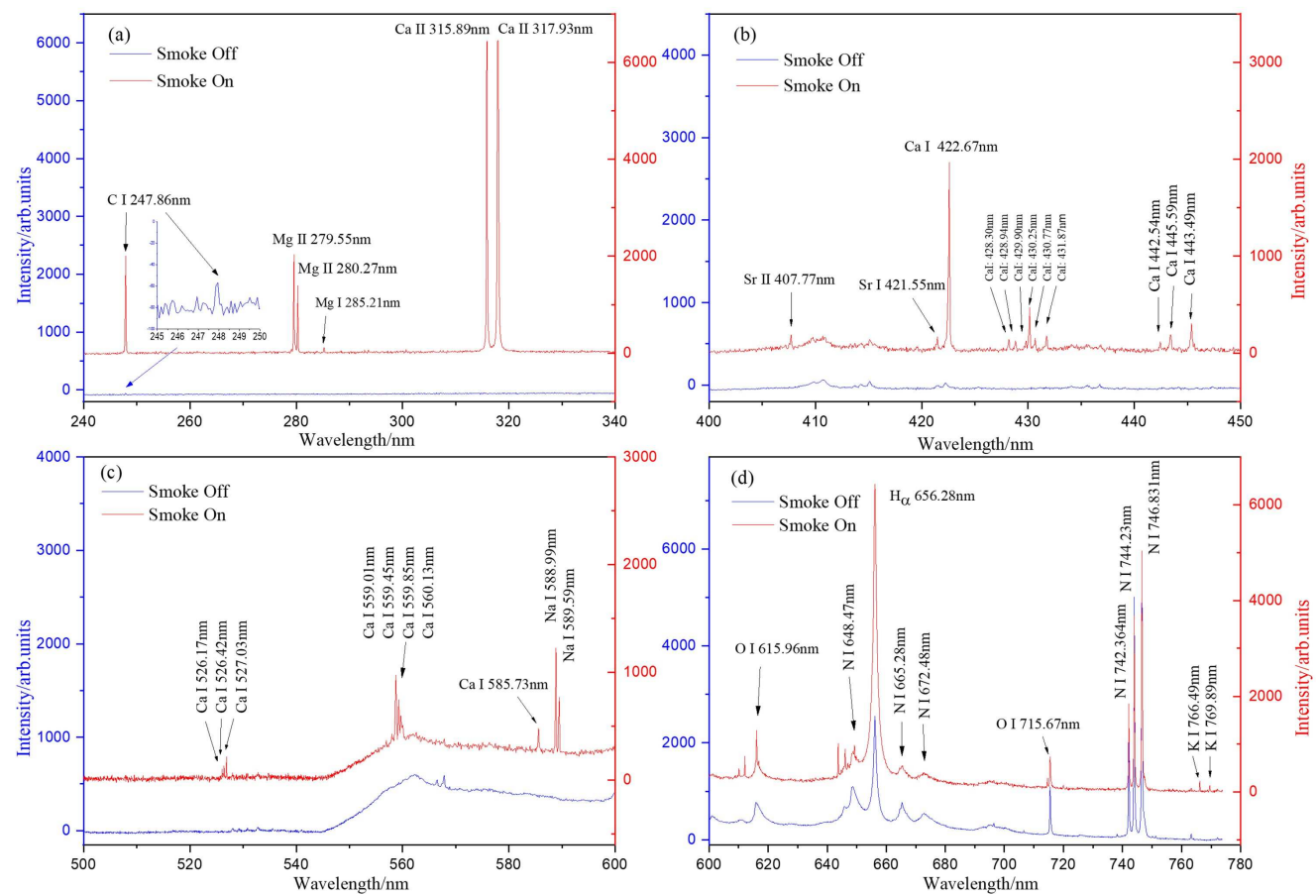

Fig. 2 The LIBS spectra of air and the smoke from a burning cigarette. (a) 240-340 nm, (b) 400-450 nm, (c) 500-600 nm, and (d) 600-780 nm (left y-axis for smoke off, right y-axis for smoke on) ${ }^{76}$ 
dust, vehicle exhaust, factory emissions, and power plant fumes. ${ }^{80,81}$ Therefore, studies on the classification and source tracing of atmospheric pollutants are necessary for detection in complex environments. The classification of samples is mainly dependent on the analysis of characteristic lines in the spectra, which could reflect the compositional information of the different pollutants. However, it is common that air pollution is caused by two or more atmospheric pollutant sources, and it is difficult to distinguish them by simple elemental analysis based on the LIBS technique. However, by combining LIBS with machine learning algorithms, it is possible to determine the pollutant sources based on their characteristics. Typically, the spectral data of characteristic lines are extracted from the spectra and used as a sample set to establish a suitable classification model. Currently, the most common algorithms used in LIBS analysis are principal component analysis (PCA), ${ }^{82-85}$ linear discriminant analysis (LDA) ${ }^{86-88}$ support vector machine (SVM), ${ }^{89-91}$ random forest (RF), ${ }^{92-94}$ and artificial neural networks (ANN). ${ }^{95-98}$ For the classification of pollutants, these methods work equally well. Lu et al. applied PCA, ${ }^{99} \mathrm{SVM}$, and back-propagation artificial neural networks (BP-ANN) for realtime in-situ detection and classification of some typical pollutants. Classification models were established according to the principal components extracted from the characteristic lines. The test experiments showed that the recognition rates of the models based on the SVM and BP-ANN algorithms were $90.00 \%$ and $93.33 \%$, respectively. The combination of these algorithms and LIBS significantly improved the recognition accuracy of the classification established based on LIBS analysis.

Isotopic detection. Nuclides of the same element with the same proton number but different neutron numbers are called isotopes, and many elements have more than two types of isotopes in nature. It is noted that stable isotopes obtained from different sources are likely to have different isotope ratios. ${ }^{100}$ Based on this principle, there have been many studies on contamination tracing via the isotopic technique. ${ }^{101-105}$ Currently, the detection of stable isotopes is based on mass spectrometry. However, mass spectrometry generally requires complicated sample pretreatment procedures, and the measurement must be performed in a vacuum environment. Moreover, it is difficult to accurately distinguish the peaks of different elements or fragments in the mass spectrum if there are more than two possibilities for the identification results. The LIBS technique is promising as a supplement or alternative for the detection and analysis of mass spectrometry owing to its merits mentioned above.

Yin and Zhang et al. carried out research on the quantitative detection of three principal $\mathrm{Pb}$ isotopes $\left({ }^{206} \mathrm{~Pb},{ }^{207} \mathrm{~Pb}\right.$, and $\left.{ }^{208} \mathrm{~Pb}\right)$ in smoke from a burning cigarette and incense based on the combination of LIBS and SPAMS. ${ }^{70,76}$ The concentration of $\mathrm{Pb}$ and the abundance ratio of isotopes were analyzed according to the obtained LIBS spectrum and mass spectrum, as shown in Fig. 3. Such studies have successfully proved that the assistance of LIBS measurements could greatly improve the identification accuracy
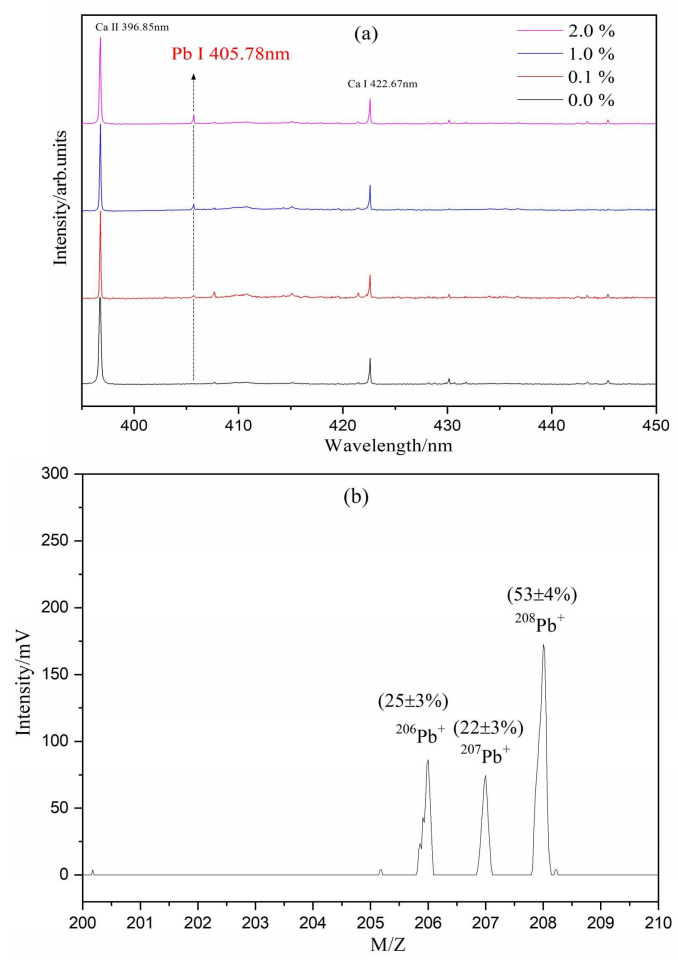

Fig. 3 (a) The variations of the spectral lines with the different concentrations of $\mathrm{Pb}$. (b) The mass spectrum of $\mathrm{Pb}$ isotope and abundance in cigarette smoke. ${ }^{76}$

of the peaks in the mass spectrum. However, measurements based on the combination of these two methods require too much time, and the drawbacks, such as complicated sample pretreatment and rigorous experimental conditions, still restrict the application of these techniques in the field of isotopic detection.

In recent years, isotopic analysis based on the LIBS technique, termed laser ablation molecular isotope spectrometry (LAMIS), has drawn significant attention. ${ }^{106,107}$ In LAMIS, both the atomic lines and molecular emission bands are recorded using a spectrometer. The characteristic atomic lines provide elemental information, whereas the molecular bands can be used for compositional analysis. Here, we take the carbon-nitrogen free radical emission band as an example to illustrate the formation of diatomic molecules in plasma and isotopic analysis based on the LAMIS technique. The temperature in the outer layer of the plasma is lower than the temperature in the center, and the molecular fragments can be directly released from the sample and combined with the molecular fragments in ambient atmosphere. ${ }^{108-110}$ The formation of $\mathrm{CN}$ radicals can be explained by the reaction of carbon in the sample with nitrogen in the air, ${ }^{111}$ as shown in Fig. 4. Carbon isotopes have two principal mass numbers, ${ }^{12} \mathrm{C}$ and ${ }^{13} \mathrm{C}$, and the variation in the mass number of carbon atoms leads to a change of the reduced mass of the $\mathrm{CN}$ molecule. Then, the emission band of $\mathrm{CN}$ shifts a certain distance because of the isotopic effect. Hence, there is a wavelength 


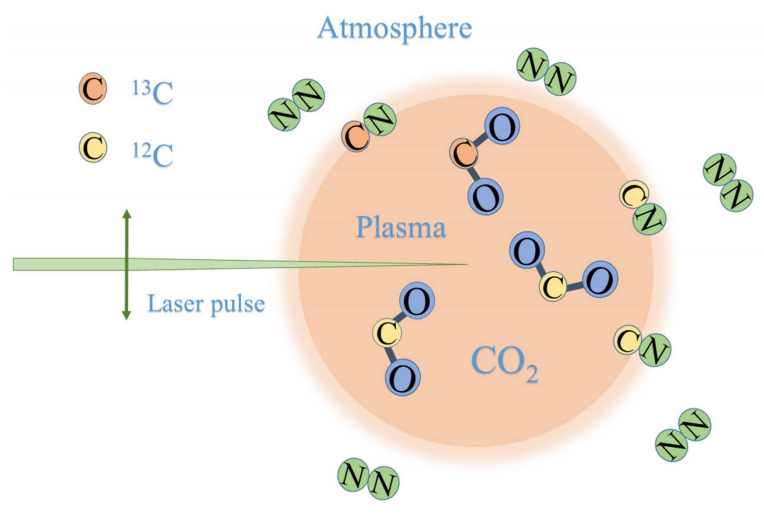

Fig. 4 The formation mechanism of $\mathrm{CN}$ radical. In the outer layer of plasma, the carbon in the sample combined with the nitrogen in the air.

difference between the emission bands of ${ }^{12} \mathrm{CN}$ and ${ }^{13} \mathrm{CN}$, and it is easy to distinguish the carbon isotopes using the LAMIS technique. Furthermore, the intensities of the molecular bands emitted from different molecules have a significant linear correlation with the abundance of each isotope, which is the foundation of the quantitative analysis of isotopes.

Zhang et al. carried out research on the online detection of carbon isotopes and studies the atmospheric carbon cycle by LIBS. ${ }^{112}$ The carbon element in the PM generated from burning coal, wood, and paper samples was determined first. Then, isotopic shifts of the $\mathrm{CN}$ molecular emission bands in the LIBS spectrum of gaseous $\mathrm{CO}_{2}$ were experimentally measured, as shown in Fig. 5. Theoretical calculations based on density functional theory were performed to obtain the energy differences of the isotopic shifts of the $\mathrm{CN}$ molecular band, as well as those of many other molecules formed by different types of isotopes. Recent research has shown that LIBS is a useful tool for the stable isotope analysis of several elements.

However, only a few types of molecular bands have been reported, and most of the free radicals have never been observed in LIBS measurements. Moreover, the isotopic effect on the molecular band was highly related to the mass number of the element. The larger the mass number, the smaller the isotopic shift of the emission band. ${ }^{106}$ Hence, it is difficult to accomplish the isotopic analysis of the heavy metal element in atmospheric pollutants merely by LIBS. Other techniques, such as mass spectrometry, must be applied in combination with LIBS.

Detection of halogens in VOCs. VOCs are the major atmospheric pollutants. VOCs are the precursors to the formation of ozone and secondary organic aerosols, such as fine PM, ${ }^{113}$ which can cause serious atmospheric environmental problems. In addition, some specific VOCs that contain bromine and chlorine atoms have long been regarded as culprits in the destruction of the ozone layer. ${ }^{114}$ 115 Therefore, the rapid direct detection of VOCs in the atmospheric environment is of great significance for environmental protection.

Most of the current studies on the LIBS technique have focused
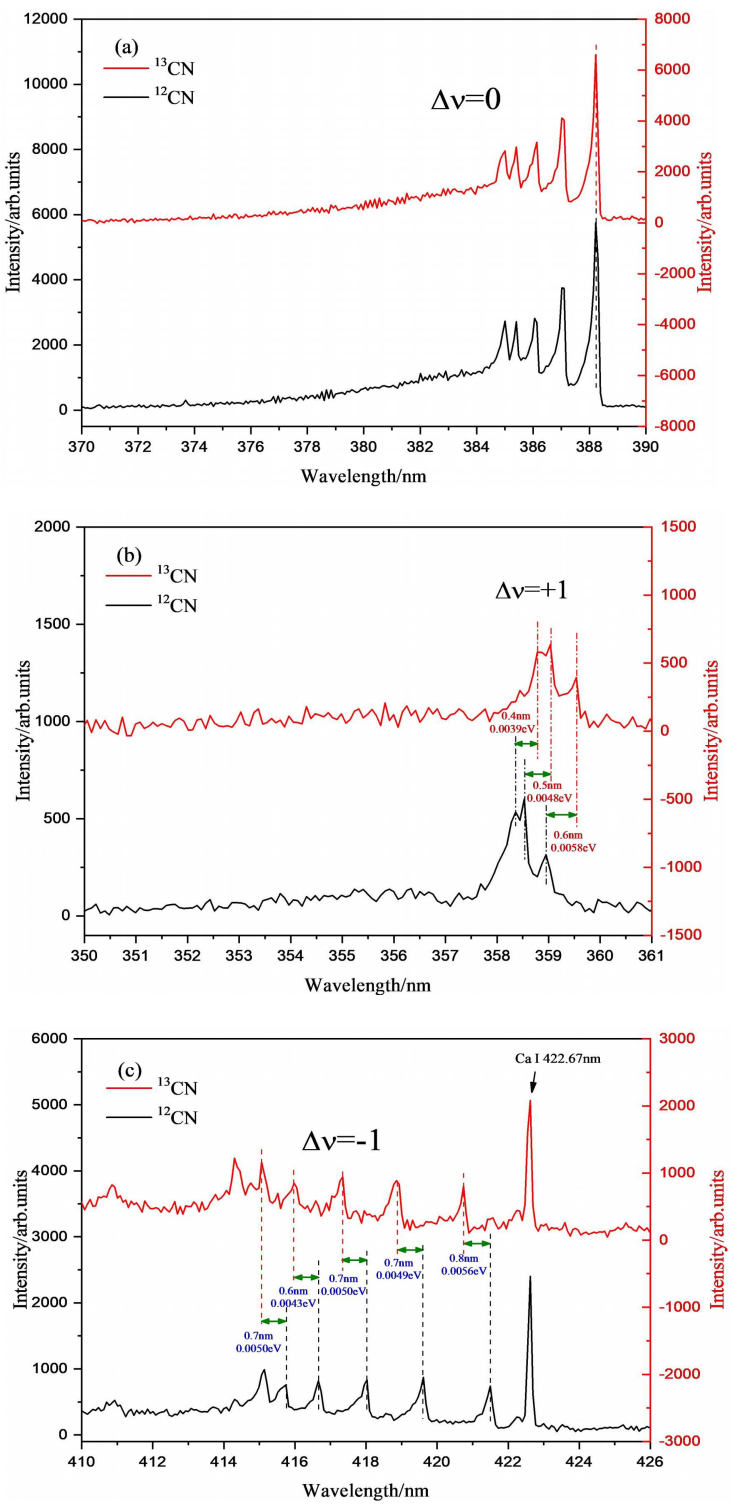

Fig. 5 The isotopic shift of $\mathrm{CN}$ molecular emission bands. (a) The isotopic shift is almost 0 when the vibrational quantum number $\Delta v$ equals 0 . (b) The emission band of the transition $\mathrm{B}^{2} \Sigma^{+}(v=1) \rightarrow \mathrm{X}^{2} \Sigma^{+}(v=0)(\Delta v=+1)$ redshifts approximately $0.6 \mathrm{~nm}$. (c) The emission band of the transition $B^{2} \Sigma^{+}(v=0)$ $\rightarrow X^{2} \Sigma^{+}(v=1)(\Delta v=-1)$ blueshifts approximately $0.8 \mathrm{~nm} .{ }^{12}$

on the qualitative and quantitative analysis of metal elements in target samples. In contrast, there are few studies on the LIBS analysis of nonmetallic elements, such as $\mathrm{F}, \mathrm{Cl}, \mathrm{Br}, \mathrm{I}$, and $\mathrm{S}$. Compared with metallic elements, the LIBS detection of nonmetallic elements, especially halogens and sulfur, presents particular difficulty for LIBS analysis because of the high ionization energy of such elements and the relative weakness of their spectral lines, ${ }^{116}$ which is unfavorable for the appearance of the characteristic emission lines in the measurements. Furthermore, most of the spectral lines of such elements lie in the vacuum ultraviolet (VUV) $(110-190 \mathrm{~nm})$ spectral range, ${ }^{117}$ and the requirement for the collection of emission spectra is so robust that it hinders the development of LIBS applications in environmental detection. 


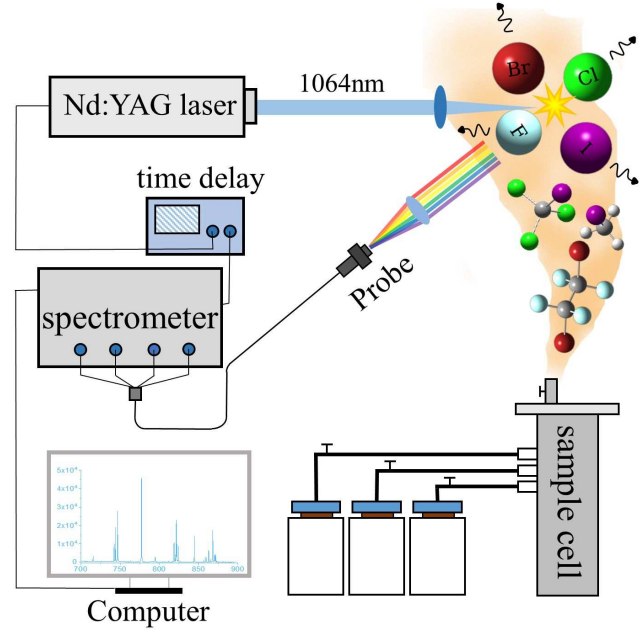

Fig. 6 Schematic of the LIBS experimental setup designed for online detection of VOCs. The home-made sample cell, which includes a tube with a valve, was used to store the gaseous sample, switch the gas flow on/off, and control the direction of gas flow. ${ }^{125}$

To address this challenging issue, there has been significant effort to enhance the ability of LIBS to detect nonmetallic elements in the last several years. The experimental environment has a significant effect on the signal strength and quality of the spectral lines of halogens. Asimellis et al. performed LIBS detection under a controlled inert gas ambient atmosphere so that $\mathrm{F}$ and $\mathrm{Cl}$ could be detected in the upper visible and near-infrared (NIR) wavelengths $(650-850 \mathrm{~nm}) .{ }^{118}$ The signal-to-noise $(\mathrm{S} / \mathrm{N})$ ratio of the spectral line was further enhanced under optimal He pressure in the range of $60 \mathrm{mbar}$. Zhang et al. detected iodine in buffer gases of $\mathrm{N}_{2}$ and air using nanosecond and picosecond breakdowns of $\mathrm{CH}_{3} \mathrm{I}$ at reduced pressure. ${ }^{119}$ The results showed that the use of buffer gases reduced the quenching rate of excited iodine in air. It was demonstrated that the interference of the continuum emission from the plasma decreased as the pressure decreased. However, it is extremely difficult to use buffer gases or create a low-pressure environment in open air. These methods are far from being recognized as realistically suitable for the detection of halogen traces in the atmosphere. These experiments can only be applied to the detection of halogens in solid or liquid samples.

In addition to optimizing the environmental parameters, determining the concentration of some nonmetallic elements by analyzing the related molecular emission in the LIBS spectra is also an effective solution in some specific cases. A recent review summarized advances in halogen detection by molecular emission. ${ }^{120}$ Gaft et al. studied the elemental analysis of halogens in minerals, ${ }^{121-122}$ including fluorine, chlorine, bromine, and iodine, using molecular emission. The authors developed corresponding detection methods for these halogens by combining them with alkali-earths and other elements to form molecules whose spectra could be easily identified, and then the analytical methods were successfully applied to real conditions. Thus, the molecular spectra enabled detection under ambient conditions with much higher sensitivity than that of F I and Cl I atomic lines. Similarly, Llamas et al. studied fluorine quantification in calcium-free samples through the analysis of $\mathrm{CaF}$ molecular bands. ${ }^{116}$ Tang et al. investigated the determination of fluorine in copper ore using

LIBS assisted by the SrF molecular emission band. ${ }^{123}$ To improve the sensitivity of detection, Nagli et al. proposed combining LIBS with molecular laser-induced fluorescence (MLIF). ${ }^{124}$ Comparing the ordinary LIBS method with LIBS-MLIF demonstrated that the combination of LIBS and MLIF significantly improved the detection sensitivity by approximately 10 times.

The LIBS detection of nonmetallic elements assisted by the above methods is realized at the cost of speed and generalizability. Furthermore, in terms of atmospheric VOCs, it is unfeasible to apply such complicated treatments in an open environment. To realize the direct detection of halogens in air, Zhang et al. designed a novel LIBS experimental system coupled with SPAMS, as shown in Fig. 6. ${ }^{125}$ Taking Halon 2402, Freon R11, and iodomethane gas as target samples, the online direct detection of $\mathrm{F}$, $\mathrm{Cl}, \mathrm{Br}$, and I elements was carried out under atmospheric pressure using an extremely strong pulse laser of $200 \mathrm{~mJ}$ as the excitation source in the LIBS system. The LIBS and SPAMS spectra of the Halon 2402 gas sample were captured, as shown in Fig. 7.

The atomic lines $(\mathrm{Br} \mathrm{I})$ and ionic lines $(\mathrm{Br}$ II) of bromine were simultaneously observed in the LIBS spectrum. The different isotopes of bromine and chlorine could be clearly distinguished at the same time based on the SPAMS analysis. It was thus demonstrated that the LIBS-SPAMS technique can provide elemental and isotopic information of halogen atoms in atmospheric VOCs. Furthermore, this method enables remote LIBS detection to meet the actual needs of halogen detection in most cases, especially in the atmosphere.

Detection of atmospheric sulfur. The LIBS detection of sulfur has the same problem as halogen detection because the strong sulfur lines in the NIST database lie within the VUV or NIR spectral range, ${ }^{126}$ which poses great difficulty in terms of capturing the emission spectra in open air. Because the spectral emission in the VUV band rapidly decays in air, studies on the detection of sulfur are carried out in a vacuum environment. Ytsma et al. used the LIBS spectra of standard geological samples to quantify sulfur and other main elements under a variety of atmospheric conditions, ${ }^{127}$ including vacuum, Mars, and Earth atmospheres. The authors established a quantification model based on multivariate analysis; however, the experimental results showed that there was poor linearity between the actual and predicted concentrations, and thus the method was impractical for determining the sulfur concentration. Kubitza et al. studied the detection of sulfur in lunar analogs at concentrations ranging from 0.5 to 4.0 at $\%$ by conducting LIBS experiments in a high-vacuum $\left(10^{-3} \mathrm{~Pa}\right)$ environment. ${ }^{128}$ Zhang et al. proposed a new analytical method for sulfur determination in sulfur-bearing powder samples 

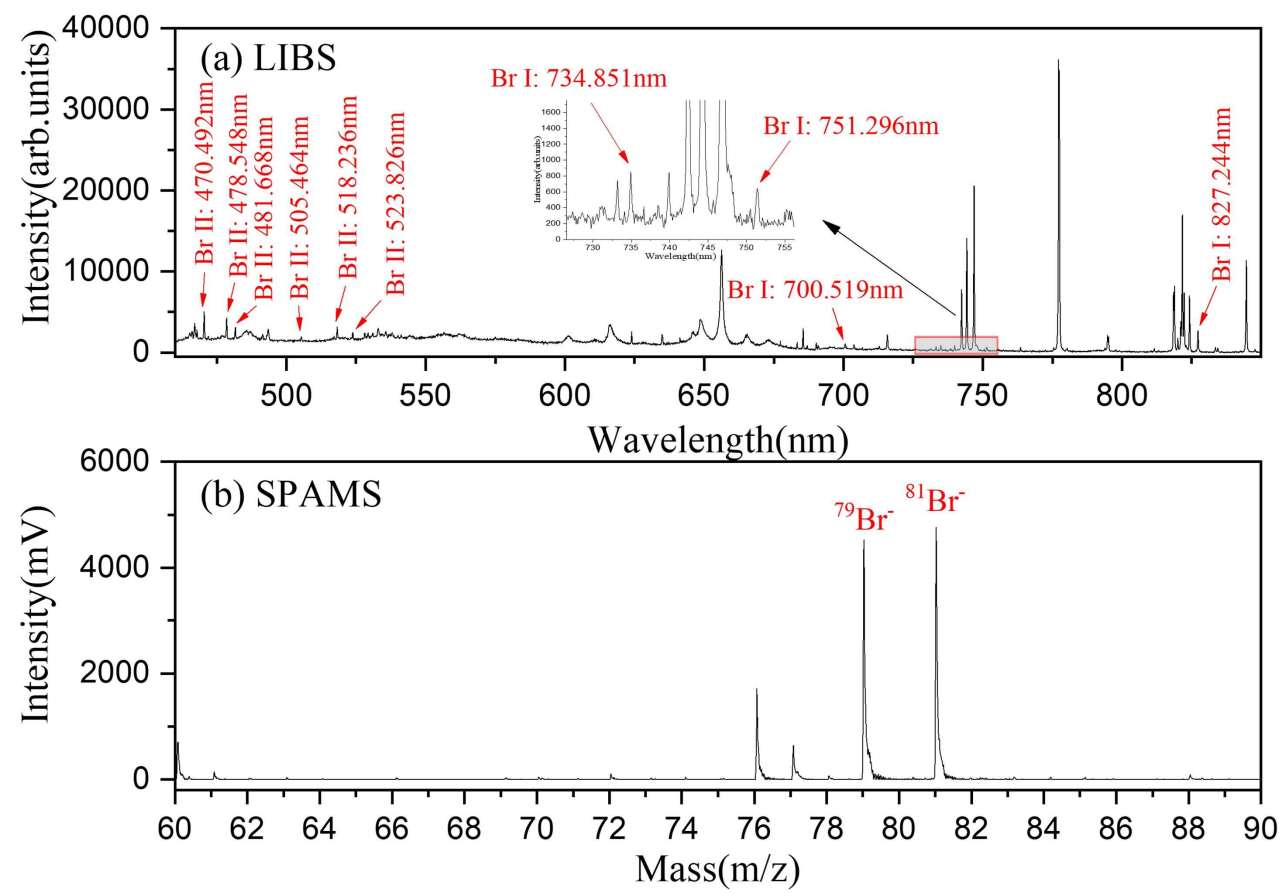

Fig. 7 The characteristic peaks of bromine in the LIBS-SPAMS spectra of Halon 2402. (a) The atomic lines (Br I) and ionic lines (Br II) of bromine in the LIBS spectrum, and (b) the mass peaks of bromine at $\mathrm{m} / \mathrm{z} 79$ and 81 in the SPAMS spectrum. ${ }^{125}$

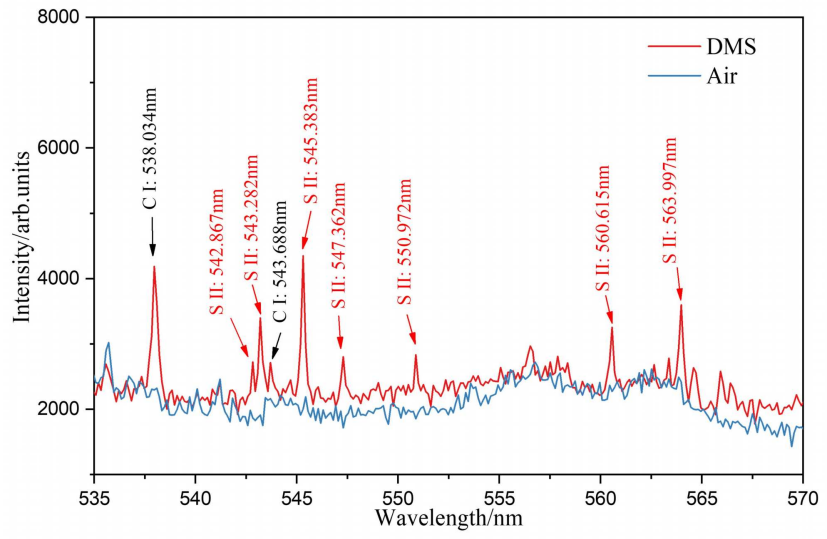

Fig. 8 The ionic lines of sulfur in the LIBS spectrum of a DMS gas sample at a laser energy of $1000 \mathrm{~mJ} /$ pulse. $^{130}$

using resonance Raman scattering combined with the LIBS technique. ${ }^{129}$ Compared to the calibration curve achieved by sulfur atomic emission, the linear coefficient $\left(R^{2}\right)$ and detection limit were significantly better.

However, this method is not suitable for LIBS detection of atmospheric sulfur because it is difficult to create a vacuum environment for detection in air. Sulfur is widely distributed in coal, petroleum, and other fossil fuels, and massive sulfide pollutants are emitted into the atmosphere during the combustion of these fuels and derivatives in factories. The detection of these atmospheric pollutants in air is of great significance for environmental protection. To apply the LIBS technique to the insitu detection of atmospheric sulfur, Zhang et al. established a novel LIBS experimental apparatus specializing in the detection of gas samples and applied it to the online direct detection of sulfur in the gas phase under atmospheric pressure. ${ }^{130}$ The characteristic ionic lines of sulfur were also clearly observed in the LIBS spectrum of a dimethyl sulfide (DMS) gas sample, as shown in Fig. 8. In addition, a quantitative calibration model of sulfur was established by fitting the intensity of the line and concentration of sulfur compounds, and the LOD of sulfur by LIBS was calculated to be $46 \mathrm{mg} / \mathrm{L}$. The experimental results also demonstrated the potential of LIBS detection of sulfur based on the analysis of sulfur ionic lines in the visible range.

However, compared to the other techniques that have been applied to the detection of sulfur, the LOD in LIBS measurements is relatively high and insufficient for the actual environmental quality control. The high LOD severely limits the application of LIBS in the in-situ detection of atmospheric sulfur. Hence, it is essential and meaningful to focus subsequent studies of this subject on the enhancement of the LIBS signal and decreasing the LOD of sulfur.

\section{CONCLUSIONS}

LIBS is a novel optical analytical method that has attracted 
significant attention in recent years. Because of its unique advantages in terms of rapid and precise response, noncontact measurement, and simultaneous multi-element analysis, the LIBS technique has been expected to play an important role in the field of environment detection or even replace conventional analytical methods under some circumstances since its inception. However, compared with the detection of solids, liquids, and aerosols, progress in atmospheric detection by LIBS was disappointingly slow in the early years. As some advanced laser techniques, including femtosecond pulse lasers, have become available, and the fundamental theory of light-matter interaction has been improved, development in this field has significantly increased in the last few decades.

In this review, a brief introduction to the in-situ online detection of the atmospheric environmental pollutants using the LIBS technique is presented, and we have highlighted recent advances in the research on the LIBS detection of atmospheric particulate matter, atmospheric pollution sources, and stable isotope abundance.

Over the past 30 years, the experimental instruments, methods, and analytical algorithms have been greatly improved, and LIBS detection now stands at its highest level of functionality. Our current research on the in-situ online detection of atmospheric environmental pollutants is focused on using LIBS to detect pollutants with extremely low concentrations and the analysis of the molecular structure of the organic matter.

\section{AUTHOR INFORMATION}

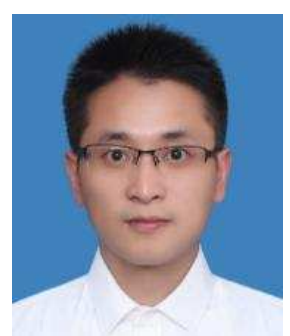

Yuzhu Liu is a full professor and vice director of Jiangsu Key Laboratory for Optoelectronic Detection of Atmosphere and Ocean at Nanjing University of Information Science and Technology (NUIST). He received his $\mathrm{PhD}$ in physics from Wuhan institute of Physics and Mathematics, Chinese Academy of Sciences (June 2011). After completing his Ph.D., he came to Paul Scherrer Institute in Switzerland for post-doctoral research. In September 2014, he returned to China and joined NUIST for professorship. His research interests include laser-induced breakdown spectroscopy, Raman spectroscopy, ultrafast molecular dynamics, photoelectron imaging technique, and time-of-flight mass spectrometry. $\mathrm{He}$ is currently working on instrumentation developments and investigations for the project of online in situ detection of elements or pollutions in the atmosphere via LIBS. He has published over 100 peer-reviewed scientific papers in ISI-indexed journals.

\section{Corresponding Author}

*Y. Z. Liu

Email address: yuzhu.liu@gmail.com

\section{Notes}

The authors declare no competing financial interest.

\section{ACKNOWLEDGMENTS}

This work was supported by National Key R\&D Program of China (2017YFC0212700), National Natural Science Foundation of China (U1932149), Natural Science Foundation of Jiangsu Province (BK20191395), Key Research and Development Program of Anhui Province (202104i07020009), and Postgraduate Research \& Practice Innovation Program of Jiangsu Province (KYCX21_0989).

\section{REFERENCES}

1. M. Kapma and E. Castanas, Environ. Pollut., 2008, 151, 362-367. https://doi.org/10.1016/j.envpol.2007.06.012

2. R. Atkinson, Atmos. Environ., 2000, 34, 2063-2101. https://doi.org/10.1016/S1352-2310(99)00460-4

3. J. H. Kroll and J. H. Seinfeld, Atmos. Environ., 2008, 42, 3593-3624. https://doi.org/10.1016/j.atmosenv.2008.01.003

4. R. S. Harmon, R. E. Russo, and R. R. Hark, Spectrochim. Acta B, 2013, 87, 11-26. https://doi.org/10.1016/j.sab.2013.05.017

5. M. Baudelet and B. W. Smith, J. Anal. At. Spectrom., 2013, 28, 624-629. https://doi.org/10.1039/C3JA50027F

6. E.F. Runge, R.W. Minck, and F.R. Bryan, Spectrochim. Acta B, 1964, 20, 733-736. https://doi.org/10.1016/0371-1951(64)80070-9

7. J. El Haddad, L. Canioni, and B. Bousquet, Spectrochim. Acta B, 2014, 101, 171-182. https://doi.org/10.1016/j.sab.2014.08.039

8. S. Shin, Y. Moon, J. Lee, H. Jang, E. Hwang, and S. Jeong, Plasma Sci. Technol., 2019, 21, 034011. https://doi.org/10.1088/2058-6272/aaed6c

9. B. Campanella, E. Grifoni, S. Legnaioli, G. Lorenzetti, S. Pagnotta, F. Sorrentino, and V. Palleschi, Spectrochim. Acta B, 2017, 134, 52-57. https://doi.org/10.1016/j.sab.2017.06.003

10. S. B. Roh, S. B. Park, S. K. Oh, E. K. Park, and W. Z. Choi, J. Mater. Cycles Waste Manage., 2018, 20, 1934-1949. https://doi.org/10.1007/s10163-018-0701-1

11. H. Jull, J. Bier, R. Künnemeyer, and P. Schaare, Spectrosc. Lett., 2018, 51, 1-9. https://doi.org/10.1080/00387010.2018.1466806

12. C. P. M. Roux, J. Rakovský, O. Musset, F. Monna, J. F. Buoncristiani, P. Pellenard, and C. Thomazo, Spectrochim. Acta B, 2018, 103-104, 63-69. https://doi.org/10.1016/j.sab.2014.11.013

13. S. Sheta, M. S. Afgan, Z. Y. Hou, S. C. Yao, L. Zhang, Z. Li, and Z. Wang, J. Anal. At. Spectrom., 2019, 34, 1047-1082. https://doi.org/10.1039/C9JA00016J

14. S. Legnaioli, B. Campanella, S. Pagnotta, F. Poggialini, and V. Palleschi, Spectrochim. Acta B, 2019, 155, 123-126. https://doi.org/10.1016/j.sab.2019.03.012

15. C. H. Yan, J. Qi, J. Ma, H. S. Tang, T. L. Zhang, and H. Li, Chemom. Intell. Lab. Syst., 2017, 167, 226-231. https://doi.org/10.1016/j.chemolab.2017.06.006

16. A. Metzinger, D. J. Palásti, É. Kovács-Széles, T. Ajtai, Z. Bozóki, 
Z. Kónya, and G. Galbács, Energy Fuels, 2016, 30, 10306-10313. https://doi.org/10.1021/acs.energyfuels.6b02279

17. J. Y. Peng, W. Y. Xie, J. D. Jiang, Z. F. Zhao, F. Zhou, and F. Liu, Foods, 2020, 9, 341. https://doi.org/10.3390/foods9030341

18. F. O. Leme, D. M. Silvestre, A. N. Nascimento, and C. S. Nomura, J. Anal. At. Spectrom., 2018, 33, 1322-1329. https://doi.org/10.1039/C8JA00115D

19. J. Wang, P. C. Zheng, H. D. Liu, and F. Liang, Anal. Methods, 2016, 8, 3204-3209. https://doi.org/10.1039/C5AY03260A

20. J. Wu, Y. Liu, Y. W. Cui, X. H. Zhao, and D. M. Dong, Biosens. Bioelectron., 2019, 142, 111508. https://doi.org/10.1016/j.bios.2019.111508

21. Y. M. Moon, J. H. Han, H. H. Choi, S. Shin, Y. C. Kim, and S. Jeong, J. Biomed. Opt., 2018, 24, 031011. https://doi.org/10.1117/1.jbo.24.3.031011

22. N. Killiny, E. Etxeberria, A. P. Flores, P. G. Blanco, T. F. Reyes, and L. P. Cabrera, Sci. Rep., 2019, 9, 2449. https://doi.org/10.1038/s41598-019-39164-8

23. N. Li, J. Guo, C. Zhang, Y. Zhang, Q. Li, Y. Tian, and R. E. Zheng, Appl. Opt., 2019, 58, 3886-3891. https://doi.org/10.1364/ao.58.003886

24. V. K. Singh, D. K. Tripathi, X. Mao, R. Russo, and V. Zorba, Appl. Spectrosc., 2019, 73, 387-394. https://doi.org/10.1177/0003702819830394

25. Rehan, M. A. Gondal, and K. Rehan, Talanta, 2018, 182, 443-449. https://doi.org/10.1016/j.talanta.2018.02.024

26. S. M. Zaytsev, I. N. Krylov, A. M. Popov, N. B. Zorov, and T. A. Labutin, Spectrochim. Acta B, 2018, 140, 65-72. https://doi.org/10.1016/j.sab.2017.12.005

27. J. J. Guo, A. S. Mahmoud, N. Li, J. J. Song, and R. E. Zheng, Plasma Sci. Technol., 2018, 21, 034022. https://doi.org/10.1088/2058-6272/aaf091

28. P. P. Sheng, L. L. Jiang, M.D. Sui, and S.L. Zhong, Spectrochim. Acta B, 2019, 154, 1-9. https://doi.org/10.1016/j.sab.2019.02.002

29. B. Thornton, T. Takahashi, T. Sato, T. Sakka, A. Tamura, A. Matsumoto, T. Nozaki, T. Ohki, and K. Ohki, Deep Sea Res., Part I., 2018, 95, 20-36. https://doi.org/10.1016/j.dsr.2014.10.006

30. S. Guirado, F. J. Fortes, V. Lazic, and J. J. Laserna, Spectrochim. Acta B, 2012, 74-75, 137-143. https://doi.org/10.1016/j.sab.2012.06.032

31. N. Murdoch, B. Chide, J. Lasue, A. Cadu, A. Sournac, M. Bassas-Portús, X. Jacob, J. Merrison, J. J. Iversen, C. Moretto, C. Velasco, L. Parès, A. Hynes, V. Godiver, R. D. Lorenz, P. Cais, P. Bernadi, S. Maurice, R. C. Wiens, and D. Mimoun, Planet. Space Sci., 2018, 165, 260-271. https://doi.org/10.1016/j.pss.2018.09.009

32. D. S. Vogt, K. Rammelkamp, S. Schröder, and H.W. Hübers, Icarus, 2018, 302, 470-482. https://doi.org/10.1016/j.icarus.2017.12.006

33. W. Rapin, P. Y. Meslin, S. Maurice, R. C. Wiens, D. Laporte, B. Chauviré, O. Gasnault, S. Schröder, P. Beck, S. Bender, O. Beyssac, A. Cousin, E. Dehouck, C. Drouet, O. Forni, M. Nachon, N. Melikechi, B. Rondeau, N. Mangold, and N. H. Thomas, Spectrochim. Acta B, 2017, 130, 82-100. https://doi.org/10.1016/j.sab.2017.02.007

34. Q. H. Zhang, Y. Z. Liu, W. Y. Yin, F. Jin, F. B. Zhou, and Y. L. Zhang, Laser Phys., 2018, 28, 085703. https://doi.org/10.1088/1555-6611/aac71c
35. L. J. Radziemski, Spectrochim. Acta B, 2002, 57, 1109-1113. https://doi.org/10.1016/S0584-8547(02)00052-6

36. S. Moncayo, S. Manzoor, J. D. Rosales, J. Anzano, and J. O. Caceres, Food Chem., 2017, 232, 322-328. http://dx.doi.org/10.1016/j.foodchem.2017.04.017

37. A. Ruas, A. Matsumoto, H. Ohba, K. Akaoka, and I. Wakaida, Spectrochim. Acta B, 2017, 131, 99-106. https://doi.org/10.1016/j.sab.2017.03.014

38. D. A. Redoglio, N. Palazzo, F. Migliorini, R. Dondè, and S. De Iuliis, Appl. Spectrosc., 2017, 72, 584-590. https://doi.org/10.1177/0003702817742314

39. Y. Wang, A. M. Chen, D. Zhang, Q. Y. Wang, S. Y. Li, Y. F. Jiang, and M. X. Jin, Phys. Plasmas., 2020, 27, 023507. https://doi.org/10.1063/1.5131772

40. I. C. García, J. M. Vadillo, and J. J. Laserna, J. Anal. At. Spectrom., 2019, 34, 2119-2125. https://doi.org/10.1039/c9ja00196d

41. J. Y. Peng, Y. He, Z. F. Zhao, J. D. Jiang, F. Zhou, F. Liu, and T. T. Shen, Environ. Pollut., 2019, 252, 1125-1132. https://doi.org/10.1016/j.envpol.2019.06.027

42. M. Burger, P. J. Skrodzki, L. A. Finney, J. Hermann, J. Nees, and I. Jovanovic, Phys. Plasmas., 2018, 25, 083115. https://doi.org/10.1063/1.5042665

43. R. Noll, C. F. Begemann, S. Connemann, C. Meinhardt, and V. Sturm, J. Anal. At. Spectrom., 2018, 33, 945-956. https://doi.org/10.1039/c8ja00076j

44. G. Galbács, Anal. Bioanal. Chem., 2015, 407, 7537-7562. https://doi.org/10.1007/s00216-015-8855-3

45. D. W. Hahn and N. Omenetto, Appl. Spectrosc., 2010, 64, 335A-336A. https://doi.org/10.1366/000370210793561691

46. D. W. Hahn and N. Omenetto, Appl. Spectrosc., 2012, 66, 347-419. https://doi.org/10.1366/11-06574

47. M. T. Jin, H. Yuan, B. Liu, J. J. Peng, L. P. Xu, and D. Z. Yang, Anal. Methods, 2020, 12, 5747-5766. https://doi.org/10.1039/D0AY01577F

48. W. T. Li, X. Y. Li, X. Li, Z. Q. Hao, Y. F. Lu, and X. Y. Zeng, Appl. Spectrosc. Rev., 2020, 55, 1-25. https://doi.org/10.1080/05704928.2018.1472102

49. X. Hu, Y. Zhang, Z. H. Ding, T. J. Wang, H. Z. Lian, Y. Y. Sun, and J. C. Wu, Atmos. Environ., 2012, 57, 146-152. https://doi.org/10.1016/j.atmosenv.2012.04.056

50. Z. J. Hu, Y. L. Shi, H. Y. Niu, and Y. Q. Cai, Atmos. Res., 2012, 104, 302-305. https://doi.org/10.1016/j.atmosres.2011.09.002

51. J. H. Kwak, G. Kim, Y. J. Kim, and K. Park, Aerosol Sci. Technol., 2012, 46, 1079-1089. http://dx.doi.org/10.1080/02786826.2012.692492

52. Q. H. Zhang, Y. Z. Liu, R. S. Zhu, F. Jin, F. B. Zhou, and W. Y. Yin, Laser \& Optoelectronics Progress, 2018, 55, 123002. https://doi.org/10.3788/LOP55.123002

53. P. Diwakar, P. Kulkarni, and E. Birch, Aerosol Sci. Technol., 2012 , 46, 316-332. http://dx.doi.org/10.1080/02786826.2011.625059

54. K. Park, G. Cho, and J. H. kwak. Aerosol Sci. Technol., 2009, 43, 375-386. https://doi.org/10.1080/02786820802662947

55. H. Maeng, H. Chae, H. Lee, G. Kim, H. Lee, K. Kim, J. Kwak, G. Cho, and K. Park, Aerosol Sci. Technol., 2017, 51, 1009-1015. https://doi.org/10.1080/02786826.2017.1344352

56. S. Saari, S. Järvinen, T. Reponen, J. M. Attipoe, P. Pasanen, J. Toivonen, and J. Keskinen, Aerosol Sci. Technol., 2016, 50, 126-132. https://doi.org/10.1080/02786826.2015.1134764

57. G. Xiong, S. Q. Li, and S. D. Tse, Spectrochim. Acta B, 2018, 140, 13-21. https://doi.org/10.1016/j.sab.2017.11.013 
58. P. Heikkilä, J. Rossi, A. Rostedt, J. Huhtala, A. Järvinen, J. Toivonen, and J. Keskinen, Aerosol Sci. Technol., 2020, 54, 837-848. https://doi.org/10.1080/02786826.2020.1727408

59. S. Wang, A. Salamova, R. A. Hites, and M. Venier, Environ. Sci. Technol., 2018, 52, 6177-6186. https://doi.org/10.1021/acs.est.8b00123

60. Y. Guan, G. Chen, Z. Cheng, B. Yan, and L. Hou, Atmos. Environ., 2017, 171, 155-164. https://doi.org/10.1016/j.atmosenv.2017.10.020

61. M. Kumar, R. K. Singh, V. Murari, A. K. Singh, R. S. Singh, and T. Banerjee, Atmos. Res., 2016, 180, 78-91. https://doi.org/10.1016/j.atmosres.2016.05.014

62. Z. Lu, D. G. Streets, Q. Zhang, S. Wang, G. R. Carmichael, Y. F. Cheng, C. Wei, M. Chin, T. Diehl, and Q. Tan, Atmos. Chem. Phys., 2010, 10, 6311-6331. https://doi.org/10.5194/acp-10-6311-2010

63. R. S. Zhu, Y. Z. Liu, Q. H. Zhang, F. B. Zhou, F. Jin, W. Y. Yin, and X. F. Zhao, Optik, 2018, 169, 77-84. https://doi.org/10.1016/j.ijleo.2018.05.035

64. W. Y. Yin, Y. Z. Liu, F. B. Zhou, R. S. Zhu, Q. H. Zhang, and F. Jin, Optik, 2018, 174, 550-557. https://doi.org/10.1016/j.ijleo.2018.08.110

65. Z. Y. Li, Z. W. Ma, T. J. Kuijp, Z. W. Yuan, and L. Huang, Sci. Total Environ., 2014, 468-469, 843-853. https://doi.org/10.1016/j.scitotenv.2013.08.090

66. C. G. Fraga, Mol. Aspects Med., 2005, 26, 235-244. https://doi.org/10.1016/j.mam.2005.07.013

67. Y. F. Qu, Q. H. Zhang, W. Y. Yin, Y. C. Hu, and Y. Z. Liu, Opt. Express, 2019, 27, A790. https://doi.org/10.1364/OE.27.00A790

68. S. C. Kuo and Y. I. Tsai, Sci. Total Environ., 2017, 584-585, 495-504. https://doi.org/10.1016/j.scitotenv.2017.01.052

69. C. Y. Kuo, Y. H. Yang, M. R. Chao, and C. W. Hu, Sci. Total Environ., 2008, 401, 44-50. https://doi.org/10.1016/j.scitotenv.2008.04.018

70. W. Y. Yin, Y. Z. Liu, Q. H. Zhang, P. F. Ding, L. Li, and G. H. Xing, Opt. Eng., 2020, 59, 026105. https://doi.org/10.1117/1.OE.59.2.026105

71. S. S. Salvi and P. J. Barnes, Lancet, 2009, 374, 1964-1965. https://doi.org/10.1016/S0140-6736(09)61303-9

72. S. A. Glantz and W.W. Parmley, Circulation, 1991, 83, 1-12. https://doi.org/10.1161/01.cir.83.1.1

73. K. K. Teo, S. Ounpuu, S. Hawken, M. Pandey, V. Valentin, D. Hunt, R. Diaz, W. Rashed, R. Freeman, L. X. Jiang, X. F. Zhang, and S. Yusuf, Lancet, 2006, 368, 647-658 https://doi.org/10.1016/s0140-6736(06)69249-0

74. M. Öberg, M.S. Jaakkola, A. Woodward, A. Peruga, and A.P. Ustün, Lancet, 2011, 377, 139-146. https://doi.org/10.1016/S0140-6736(10)61388-8

75. J. Barnoya and S.A. Glantz, Circulation., 2005, 111, 2684-2698. https://doi.org/10.1161/circulationaha.104.492215

76. Q. H. Zhang, Y. Z. Liu, W. Y. Yin, Y. H. Yan, L. Li, and G. H. Xing, Chemosphere., 2020, 242, 125184. https://doi.org/10.1016/j.chemosphere.2019.125184

77. X. J. Zhao, P. S. Zhao, J. Xu, W. Meng, W. W. Pu, F. Dong, D. He, and Q. F. Shi, Atmos. Chem. Phys., 2013, 13, 5685-5696. https://doi.org/10.5194/acp-13-5685-2013

78. Y. L. Sun, Q. Jiang, Z. F. Wang, P. Q. Fu, J. Li, T. Yang, and Y. Yin, J. Geophys. Res. Atmos., 2013, 119, 4380-4398. https://doi.org/10.1002/2014JD021641
79. M. O. Andreae, O. Schmid, H. Yang, D. Chand, J. Z. Yu L. M. Zeng, and Y. H. Zhang, Atmos. Environ., 2008, 42, 6335-6350. https://doi.org/10.1016/j.atmosenv.2008.01.030

80. S. T. Massie, O. Torres, and S. J. Smith, J. Geophys. Res. Atmos., 2004, 109, D18211. https://doi.org/10.1029/2004JD004620

81. D.G. Streets and S.T. Waldhoff, Atmos. Environ., 2000, 34 363-374. https://doi.org/10.1016/S1352-2310(99)00167-3

82. S. Chatterjee, M. Singh, B. P. Biswal, U. K. Sinha, S. Patbhaje, and A. Sarkar, Anal. Bioanal. Chem., 2019, 411, 2855-2866. https://doi.org/10.1007/s00216-019-01731-3

83. W. L. Liao, Q. Y. Lin, S. C. Xie, Y. He, Y. H. Tian, and Y. X. Duan, Anal. Chim. Acta, 2018, 1043, 64-71. https://doi.org/10.1016/j.aca.2018.06.058

84. P. Pořízka, J. Klus, E. Képeš, D. Prochazka, D. W. Hahn, and J. Kaiser, Spectrochim. Acta B, 2018, 148, 65-82. https://doi.org/10.1016/j.sab.2018.05.030

85. A. K. Shaik, Ajmathulla, and V. R. Soma, Opt. Lett., 2018, 43, 3465. https://doi.org/10.1364/ol.43.003465

86. Z. F. Zhao, L. Chen, F. Liu, F. Zhou, J. Y. Peng, and M. H. Sun, Sensors, 2020, 20, 1878. https://doi.org/10.3390/s20071878

87. J. J. Yan, P. Yang, R. Zhou, S. H. Li, K. Liu, W. Zhang, X. Y. Li, D. Z. Wang, and Y. Lu, Anal. Methods, 2019, 11, 5177-5184. https://doi.org/10.1039/c9ay01524h

88. G. Guo, G. H. Niu, Q. Shi, Q. Y. Lin, D. Tian, and Y. X. Duan, Anal. Methods, 2019, 11, 3006-3013. https://doi.org/10.1039/c9ay00890j

89. O. Gazeli, E. Bellou, D. Stefas, and S. Couris, Food Chem., 2020, 302, 125329. https://doi.org/10.1016/j.foodchem.2019.125329

90. H. B. Peng, G. H. Chen, X. X. Chen, Z. M. Lu, and S. C. Yao, Plasma Sci. Technol., 2018, 21, 034008. https://doi.org/10.1088/2058-6272/aaebc4

91. J. Wang, L. Li, P. Yang, Y. Chen, Y. Zhu, M. Tong, Z. Q. Hao, and X. Y. Li, Lasers Med. Sci., 2018, 33, 1381-1386. https://doi.org/10.1007/s10103-018-2500-2

92. H. Tang, T. Zhang, X. Yang, and H. Li, Anal. Methods, 2015, 7, 9171-9176. https://doi.org/10.1039/c5ay02208h

93. N. Melikechi, Y. Markushin, D. C. Connolly, J. Lasue, E. Ewusi-Annan, and S. Makrogiannis, Spectrochim. Acta B, 2016, 123, 33-41. https://doi.org/10.1016/j.sab.2016.07.008

94. L. Y. Zhan, X. H. Ma, W. Q. Fang, R. Wang, Z. S. Liu, Y. Song, and H. F. Zhao, Plasma Sci. Technol., 2019, 21, 034018 https://doi.org/10.1088/2058-6272/aaf7bf

95. J. Alvarez, M. Velásquez, A. K. Myakalwar, C. Sandoval, R. Fuentes, R. Castillo, D. Sbarbaro, and J. Yañez, J. Anal. At. Spectrom., 2019, 34, 2459-2468. https://doi.org/10.1039/c9ja00271e

96. R. Junjuri and M.K. Gundawar, J. Anal. At. Spectrom., 2019, 34, 1683-1692. https://doi.org/10.1039/c9ja00102f

97. M. Yelameli, B. Thornton, T. Takahashi, T. Weerakoon, and K. Ishii, J. Chemom., 2018, 33, 3092. https://doi.org/10.1002/cem.3092

98. P. Yang, R. Zhou, W. Zhang, S. S. Tang, Z. Q. Hao, X. Y. Li, Y. F. Lu, and X. Y. Zeng, Appl. Opt., 2018, 57, 8297-8302. https://doi.org/10.1364/AO.57.008297

99. X. Lu, Y. Z. Liu, Y. B. Zhou, Q. H. Zhang, J. J. Cao, and Y. Chen, Spectrochim. Acta B, 2020, 170, 105901. https://doi.org/10.1016/j.sab.2020.105901

100. A. A. Bol'shakov, X. L. Mao, J. Jain, D. L. McIntyre, and 
R. E. Russo, Spectrochim. Acta B, 2015, 113, 106-112. https://doi.org/10.1016/j.sab.2015.08.007

101. C. S. Lee, X. D. Li, W. Z. Shi, S. C. Cheung, and I. Thornton, Sci. Total Environ., 2006, 356, 45-61. https://doi.org/10.1016/j.scitotenv.2005.03.024

102. H.F. Cheng and Y.N. Hu, Environ. Pollut., 2010, 158, 1134-1146. https://doi.org/10.1016/j.envpol.2009.12.028

103. L. Hernandez, A. Probst, J. L. Probst, and E. Ulrich, Sci. Total Environ., 2003, 312, 195-219. https://doi.org/10.1016/S0048-9697(03)00223-7

104. C. C. M. Ip, X. D. Li, G. Zhang, O. W. H. Wai, and Y. S. Li, Environ. Pollut., 2007, 147, 311-323. https://doi.org/10.1016/j.envpol.2006.06.028

105. B. J. Vanderford and S. A. Snyder, Environ. Sci. Technol., 2006, 40 , 7312-7320. https://doi.org/10.1021/es0613198

106. R. E. Russo, A. A. Bol'shakov, X. L. Mao, C. P. McKay, D. L. Perry, and O. Sorkhabi, Spectrochim. Acta B, 2011, 66, 99-104. https://doi.org/10.1016/j.sab.2011.01.007

107. A. A. Bol'shakov, X. Mao, J. J. Gonz'alez, and R. E. Russo, J. Anal. At. Spectrom., 2016, 31, 119-134. https://doi.org/10.1039/C5JA00310E

108. Z. H. Zhu, J. M. Li, Z. Q. Hao, S. S. Tang, Y. Tang, L. B. Guo, X. Y. Li, X. Y. Zeng, and Y. F. Lu, Opt. Express, 2019, 27, 470-482. https://doi.org/10.1364/OE.27.000470

109. L. B. Guo, Z. H. Zhu, J. M. Li, Y. Tang, S. S Tang, Z. Q. Hao, X. Y. Li, Y. F. Lu, and X. Y. Zeng, Opt. Express, 2018, 26, 2634-2642. https://doi.org/10.1364/OE.26.002634

110. S. H. Amiri, S. M. R. Darbani, and H. Saghafifar, Spectrochim. Acta B, 2018, 150, 86-91. https://doi.org/10.1016/j.sab.2018.10.012

111. A. Kushwaha and R.K. Thareja, Appl. Opt., 2008, 47, G65. https://doi.org/10.1364/ao.47.000g65

112. Q. H. Zhang, Y. Z. Liu, W. Y. Yin, Y. H. Yan, Q. Y. Tang, and G. H. Xing, J. Anal. At. Spectrom., 2020, 35, 341-346. https://doi.org/10.1039/c9ja00384c

113. M. Kapma and E. Castanas, Environ. Pollution, 2008, 151, 362-367. https://doi.org/10.1016/j.envpol.2007.06.012

114. M. J. Molina and F. S. Rowland, Nature, 1974, 249, 810-812. https://www.nature.com/articles/249810a0

115. W. R. Simpson, R. von Glasow, K. Riedel3, P. Anderson, P. Ariya, J. Bottenheim, J. Burrows, L. J. Carpenter, U. Frieß, M. E. Goodsite, D. Heard, M. Hutterli, H. W. Jacobi, L. Kaleschke, B. Neff, J. Plane, U. Platt, A. Richter, H. Roscoe, R. Sander, P. Shepson, J. Sodeau, A. Steffen, T. Wagner, and E. Wolff, Atmos. Chem. Phys., 2007, 7, 4375-4418. https://doi.org/10.5194/acp-7-4375-2007
116. C.A. Llamas, J. Pisonero, and N. Bordel, J. Anal. At. Spectrom., 2017, 32, 162-166. https://doi.org/10.1039/c6ja00386a

117. M. Gaft, L. Nagli, Y. Raichlin, F. Pelascini, G. Panzer, and V. Motto Ros, Spectrochim. Acta B, 2019, 157, 47-52. https://doi.org/10.1016/j.sab.2019.05.003

118. G. Asimellis, S. Hamilton, A. Giannoudakos, and M. Kompitsas, Spectrochim. Acta B, 2005, 60, 1132-1139. https://doi.org/10.1016/j.sab.2005.05.035

119. X. B. Zhang, Y. Deguchi, Z. Z. Wang, J. J. Yan, and J. P. Liu, J. Anal. At. Spectrom., 2014, 29, 1082-1089. https://doi.org/10.1039/C4JA00044G

120. M. Gaft, L. Nagli, I. Gornushkin, and Y. Raichlin, Spectrochim. Acta B, 2020, 173, 105989. https://doi.org/10.1016/j.sab.2020.105989

121. M. Gaft, L. Nagli, N. Eliezer, Y. Groisman, and O. Forni, Spectrochim. Acta B, 2014, 98, 39-47. http://dx.doi.org/10.1016/j.sab.2014.05.011

122. M. Gaft, L. Nagli, Y. Raichlin, F. Pelascini, G. Panzer, and V. M. Ros., Spectrochim. Acta B, 2019, 157, 47-52. https://doi.org/10.1016/j.sab.2019.05.003

123. Z. Y. Tang, R. Zhou, Z. Q. Hao, W. Zhang, Q. Z. Li, Q. D. Zeng, X. Y. Li, X. Y. Zeng, and Y. F. Lu, J. Anal. At. Spectrom., 2020, 35, 754-761. https://doi.org/10.1039/C9JA00407F

124. L. Nagli and M. Gaft. Appl. Spectrosc., 2016, 70, 585-592. https://doi.org/10.1177/0003702816631292

125. Q.H. Zhang, Y.Z. Liu, Y. Chen, Y.Z. Zhangcheng, Z.M. Zhuo, and L. Li, Opt. Express, 2020, 28, 22855. https://doi.org/10.1364/OE.400324

126. M. Gaft, L. Nagli, I. Fasaki, M. Kompitsas, and G. Wilsch. Spectrochim. Acta B, 2009, 64, 1098-1104. https://doi.org/10.1016/j.sab.2009.07.010

127. C.R. Ytsma and M.D. Dyar, Spectrochim. Acta B, 2019, 162, 105715. https://doi.org/10.1016/j.sab.2019.105715

128. S. Kubitzaa, S. Schrödera, E. Dietza, S. Frohmanna, P.B. Hansena, K. Rammelkampa, D. Sebastian, M. Genscha, and H.W. Hübersa, Spectrochim. Acta B, 2020, 174, 105990. https://doi.org/10.1016/j.sab.2020.105990

129. W. Zhang, R. Zhou, K. Liu, J.J. Yan, Q.Z. Li, Z.Y. Tang, X.Y. Li, Q.D. Zeng, and X.Y. Zeng, Talanta, 2020, 216, 120968. https://doi.org/10.1016/j.talanta.2020.120968

130. Q.H. Zhang, Y. Chen, and Y.Z. Liu, J. Anal. At. Spectrom., 2021 , 36, 1028-1033. https://doi.org/10.1039/d1ja00017a 